\title{
Intercultural Competence and Study Abroad Programs-A Mixed Method Study
}

\author{
Liqin Tang ${ }^{1 \& 2}$, John Matt ${ }^{1}$, Patty Kero ${ }^{1}$ \\ ${ }^{1}$ Department of Educational Leadership, College of Education, University of Montana, Missoula, Montana, U.S.A \\ ${ }^{2}$ Department of English, College of Foreign Languages, Jilin Normal University, Siping, China \\ Correspondence: Liqin Tang, Department of Educational Leadership, University of Montana
}

Received: July 18, 2021

Accepted: August 9, $2021 \quad$ Online Published: August 12, 2021

doi:10.11114/jets.v9i8.5323

URL: https://doi.org/10.11114/jets.v9i8.5323

\begin{abstract}
The purpose of this mixed methods study was to investigate the intercultural competence (IC) level of college students, explore whether there is a statistically significant difference in the IC level between students with study abroad (SA) experience and those without SA experience, and examine their attitudes, ideas and experiences about SA programs and intercultural communication. Data collected from online questionnaires and Zoom interviews were examined through the lens of Hall's the Iceberg Analogy of Culture and M. J. Bennett's Developmental Model of Intercultural Sensitivity (DMIS), which were also used as the conceptual framework in this study. Both quantitative and qualitative results indicated the IC level of college students was high, reaching up to the acceptance stage or/and adaptation stage of Bennett's DMIS. Quantitative study showed that the IC level of students who participated in SA programs was higher than those who didn't.
\end{abstract}

Keywords: intercultural competence (IC), study abroad programs (SA), a mixed method

\section{Introduction}

With the development of globalization and internationalization, intercultural competence (IC) has gained great importance in all fields. For college students, intercultural competence is a requisite factor for successful cross-cultural communication and qualified global citizens. There are many ways for students to experience cultural differences and thus create greater potential to develop their IC (Rust et al., 2013). Research demonstrated that participating in study abroad (SA) programs is one way to get access to the cultural differences. SA programs are expected to "transform a student's worldview and provide the necessary knowledge and skills to successfully interact with people from different cultural backgrounds" (Pongitory, 2020, pp. 2-3). Some studies found intercultural competence (IC) can be improved or increased through study abroad (SA). Other studies also discovered there was growth in undergraduates' intercultural competence even in short-term study abroad (SA) programs. Much research focuses on SA programs and IC, and the methods are comparatively onefold, either quantitative or qualitative. However, intercultural competence is a complex issue. Some outstanding researchers in this field, such as Deardorff (2006), stated that a mix of quantitative and qualitative methods is the best way to study complicated issues of IC. In this study, a mixed method has been employed to assess the IC of college students, explore whether there is a statistically significant difference in IC levels between students having SA experience and those who do not have SA experience, and examine the college students' attitudes and ideas about SA programs and IC interactions.

\section{Literature Review}

\subsection{Definitions of Culture and Intercultural Competence}

\subsubsection{Culture}

There are many definitions and concepts of culture applied by researchers in different fields. Lustig \& Koester (2013) pointed out "John R. Baldwin and his colleagues have listed over three hundred meanings for culture" (p. 25). In this study, culture is "a learned set of shared interpretations about beliefs, values, norms, and social practices, which affect the behaviors of a relatively large group of people" (Lustig \& Koester, 2013, p. 25). This definition is adopted because it is beneficial for people to understand the relationship and link between culture and communication in order to improve IC (Lustig \& Koester, 2013). "Understanding what elements influence values and traits of a culture encourages people 
to take a more objective rather than a staunchly value-laden view of the world" (Wickline et al, 2020, p. 128). Therefore, people may better identify shared goals and values by understanding other cultures (Wickline et al., 2020).

\subsubsection{Intercultural Competence (IC)}

"Today, the importance of intercultural competence in both global and domestic contexts is well recognized" (Hammer et al., 2003, p. 421). Scholars and researchers have been working on the concept of IC for many years, but there is no consensus on terminology, which includes “... communicative competence, cross-cultural adaptation, cross-cultural awareness, cross-cultural communication, cultural competence, cultural or intercultural sensitivity, effective intergroup communication, ethnorelativity, intercultural cooperation, global competitive intelligence, global competence, international competence, international communication, intercultural interaction, metaphoric competence, transcultural communication, and so forth." (Fantini, 2009, p. 457). While in this study, the term of intercultural competence (IC) has been adopted. Deardorff (2009) categorized IC into five categories: knowledge, attitudes, skills, internal outcomes and external outcomes and defined IC as "effective and appropriate behavior and communication in intercultural situations" (p. 33). This study has utilized Deardorff's definition, because it served the purpose of this study well.

\subsection{Study Abroad and Intercultural Competence}

SA experiences have been widely "hailed and assumed as one of the best ways students can increase in their IC during their years at college" (Wickline et al., 2020, p. 130). Numerous research indicated intercultural competence (IC) has been improved via study abroad (SA) (Williams, 2005; Braskamp et al, 2009; Anderson \& Lawton, 2011; Stebleton et al., 2013; Stemler et al., 2014; Anderson \& Lawton, 2015; Heinzmann et al., 2015; Petrie-Wyman et al., 2020; Wickline et al., 2020). Some research also demonstrated there was growth in undergraduates' IC even in short-term study abroad (SA) programs (Anderson et al., 2005; Kurt et al., 2013; Mapp, 2012; Olson \& Lalley, 2012).

Multiple researchers used quantitative methods to investigate IC and SA. Anderson et al. (2005) found the positive effect of short-term SA on intercultural sensitivity through the quantitative method, using the instrument of Intercultural Development Inventory (IDI). Strange and Gilbson (2017) utilized quantitative method to explore "the transformative learning potential of university level study abroad programs and to assess the influence of experiential learning components (operationalized as program type) and program length on transformative learning" (p. 90). A most recent study, done by Wickline et al. (2020) also used a quantitative research method to investigate undergraduate students' IC, and stressed that SA is a viable way, but not the only way to increase IC. Some researchers used qualitative methods. Marx and Moss (2011) used qualitative method to explore students' intercultural development during a semester-long teacher education program. Findings from this study revealed that "participation in the [SA] program positively influenced intercultural development" (Marx \& Moss, 2011, p. 35). Another case in point is Maharaja (2018) investigated the influence of SA on the development of students' IC and personal development via qualitative research method. There is a trend that more researchers use mixed methods to explore IC and SA. King et al. (2013) conducted a mixed method study on how college students experience intercultural learning through different approaches and found that participating in SA programs and doing personal reflection improve intercultural learning. Tarchi et al (2019) assessed SA students' orientations to cultural difference with mixed methods, including a self-report questionnaire of intercultural sensitivity and "oral narratives [video logs] of critical incidents in the foreign culture" (p. 873). They stressed the effectiveness of using video logs to facilitate intercultural sensitivity as a means of narratives. Most recently, Pongitory (2020) used "a sequential explanatory two-phase mixed methods design" (p. iii) in her doctoral dissertation to examine the influence of experiential learning embedded in SA sojourns on students' development of global competence.

\section{Conceptual Framework}

In this study, two models form the conceptual or theoretical framework: Edward T. Hall's the Iceberg Analogy of Culture and M. J. Bennett's Developmental Model of Intercultural Sensitivity (DMIS). Hall once declared that culture is like an iceberg: the tip or visible portion above the water is small, belonging to external culture, and the middle and bottom or hidden portion under the water are large, comprising nearly 90 percent, which is internal culture (Weaver, 1998). Weaver (1998) cited Hall's idea that internal culture is dominant over external culture. The following figure is taken from Sakurauchi's (2014) doctoral dissertation, and this cultural iceberg model shows two levels of culture: internal culture and external culture. Internal culture has two sublevels: one sublevel lies in the middle of the iceberg, including values, norms and beliefs, and the other sublevel lies at the bottom and consists of basic assumptions. External culture is above the water, which is made up of communication, patterns and behaviors. (pp. 24-25) 


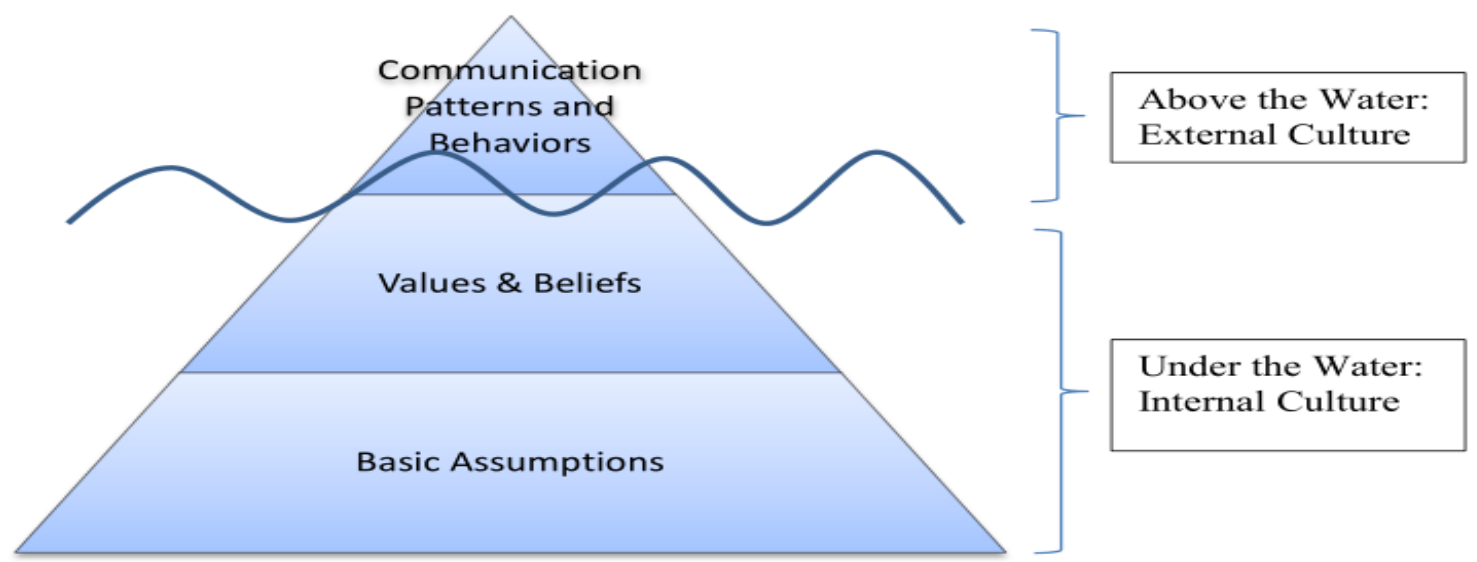

Figure 1. Cultural Iceberg Model from Weaver's Iceberg Analogy of Culture (Sakurauchi, 2014, p. 25)

The other model concerning intercultural competence is put forward by M. J. Bennett's (2004): Developmental Model of Intercultural Sensitivity (DMIS). Bennett (2004) argued that "as people became more interculturally competent it seemed that there was a major change in the quality of their experience", which he called "the move from ethnocentrism to ethnorelativism". (p. 62):

There also seemed be six distinct kinds of experience spread across the continuum

from ethnocentrism and ethnorelativism. The most ethnocentric experience was named

the Denial of cultural difference, followed by the Defense against cultural difference. In

the middle of the continuum the Minimization of cultural difference seemed to be a

transition from the more virulent forms of ethnocentrism to a more benign form, leading

to the ethnorelative Acceptance of cultural difference. At the heart of ethnorelativism was

Adaptation to cultural difference, followed in some cases by the Integration of cultural

difference into identity (Bennett, 2004, p. 62).

Figure two is Bennett's Developmental Model of Intercultural Sensitivity (DMIS).



\section{ETHNOCENTRISM}

\section{ETHNORELATIVISM}

Figure 2. Bennett's Developmental Model of Intercultural Sensitivity (DMIS) (Sakurauchi, 2014, p. 39)

This study is built upon the aforementioned two models, and the conceptual framework of it is mainly within a constructivist and action-oriented paradigm.

\section{The Empirical Study}

In order to have a better understanding of college students' IC, as well as their attitudes, ideas and experiences concerning study abroad programs and intercultural interactions, this empirical study adopted a mixed method, including an online survey and interviews via Zoom. The quantitative research questions are addressed as follows:

(1) What is the IC level of overall college students at a flagship university in the northwest, United States? What are the IC levels of students who participated in study abroad programs and those who didn't participate respectively?

(2) Is there any statistically significant difference in IC between students with SA experience and those without SA experience? 
The qualitative central question is

(1) How do college students at the at a flagship university in the northwest, United States value SA program and IC communication?

\subsection{Methodology}

\subsubsection{Population and Sample}

The whole population of the undergraduate students at a flagship university in the northwest, United States, is 6,321 (up to the fall, 2020). With the help of University Data Office, there were 5,371 undergraduate students on the main campus who received an email invitation to participate in the survey of intercultural competence. Finally, there were 468 students who singed the informed consent form and responded to the survey. There were 385 valid responses, including 350 students without study abroad experience and 35 students with study abroad experience. Among them, eight out of 69 volunteers were selected to participate in the interview via Zoom.

\subsubsection{Research Instrument}

A self-report questionnaire on Qualtrics and interviews via Zoom were used to collect data. The first instrument used in this study include a revised Intercultural competence questionnaire (ICQ) developed by Mirzaei and Forouzandeh (2013), which consists of two sections. The first section is about demographic information, such as, age, ethnicity, the lengths of travelling and studying outside the U.S., and grade level, (first year, second year, third year, fourth year and up). The second section is the Intercultural Competence Questionnaire (ICQ), including 23 statements to measure students' intercultural competence. The first 22 questions use a four-point Likert scale with a range of $1=$ strongly disagree to $4=$ strongly agree and the last question 23 is self-evaluation of students' IC level, with 3 options from low, medium to high. Students are also required to give the reasons for their self-evaluation.

Secondly, an invitation to interview was provided at the end of the online survey on Qualtrics. Eight volunteers have been recruited. Four students have SA experience and four students have not SA experience. The aim of the interviews was to crosscheck the survey results and to offer more insights into how participants view SA experience, cultural differences and intercultural communication. The interview protocol is used to collect data during the interview, which is made up of two sections. Section one is demographic information which includes such elements as interview date and time; participant's gender; participant's grade level, major, and race or ethnicity. Section two includes 8 open-ended questions (Among them, the second question explores whether students have SA experience, including 4 sub-questions) designed to learn about the participant's attitude, thoughts and experiences concerning SA program and intercultural communication.

The validity and reliability of the IC instrument were established by the developers, Mirzaei and Forouzandeh (2013), "polit-tested with 10 students and modified items were administered to 100 students to ensure validity and reliability of the instrument" (p. 307). Cronbach alpha reliability coefficient is alpha $=.71$. In order to improve the reliability and serve the purpose of this study better, the researchers revised IC instrument and finally the Cronbach alpha of the revised version was improved to .84 .

For the qualitative part of this study, in order to guarantee the quality and verification, accuracy and trustworthiness have been established by various methods, such as data collected from multiple sources (including individual interview transcriptions; the emerging categories based on the interview transcription; the interviewer's notes, and participant demographic data.) and consensual validation through the review process.

\subsubsection{Data Collection and Analysis}

After the questionnaires were collected, all quantitative data were input into the computer, and statistical tests were conducted by means of IBM SPSS Statistics 25 . Because the scores about IC were obtained by Likert scales, they were treated as ordinal scale of measurement, which indicated that non-parametric tests should be used to analyze the data. First, descriptive statistics were used to determine overall students' IC level, as well as IC levels of students with and without study abroad experience respectively. The researchers determined cut-off points to make a judgement about participants' IC level (Table 1), based on Saricoban and Oz's (2014) IC Criteria Table. For Table 1, the median scores range from 66-88 are considered High. Moderate if the median scores from 44-65. Low if the median scores from 22-43. Then, Mann-Whitney $U$ was used to investigate the difference in the levels of intercultural competence between students with SA experience and those without such experience. Table 1 shows the criteria of intercultural competence (IC) level. Bennett's DMIS has been quantified based on the criteria of IC level --- Integration stage: 78-88; Adaptation stage: 67-77; Acceptance stage: 56-66; Minimization stage: 45-55; Defense/reverse stage: 34-44; Denial stage: 22-33 (see Table 2): 
Table 1. Criteria of IC Level

\begin{tabular}{ll}
\hline IC Level & Median \\
\hline High & $66-88$ \\
Moderate & $44-65$ \\
Low & $22-43$
\end{tabular}

Table 2. Quantified Bennett's Developmental Model of Intercultural Sensitivity (DMIS)

\begin{tabular}{|c|c|c|}
\hline Bennett's Stage & Description of the stage & Criteria of scores \\
\hline Denial & $\begin{array}{l}\text { Individuals deny the existence of other cultures } \\
\text { or the differences between them. }\end{array}$ & $22-33$ \\
\hline Defense/reverse & $\begin{array}{l}\text { Individuals react against the threat of other } \\
\text { cultures by denigrating the other cultures and } \\
\text { promoting the superiority on one's own culture. }\end{array}$ & $34-44$ \\
\hline Minimization & $\begin{array}{l}\text { Individuals acknowledge cultural differences on } \\
\text { the surface but consider all cultures as } \\
\text { fundamentally similar. }\end{array}$ & $45-55$ \\
\hline Acceptance & $\begin{array}{l}\text { Individuals accept and respect cultural } \\
\text { differences with regard to behavior and values. }\end{array}$ & $56-66$ \\
\hline Adaptation & $\begin{array}{l}\text { Individuals develop the ability to shift their } \\
\text { frame of reference to other culturally diverse } \\
\text { worldviews through empathy and pluralism. }\end{array}$ & $67-77$ \\
\hline integration & $\begin{array}{l}\text { Individuals expand and incorporate other } \\
\text { worldviews into their own worldview. }\end{array}$ & $78-88$ \\
\hline
\end{tabular}

[This table is built based on Stemler et al.'s (2014) table 3, p. 33]

The interviews were conducted after quantitative data had been collected from Qualtrics. At the very beginning of the interview, participants were informed that all information from the interview would be confidential using a coding protocol to identify each participant's data and that the interviews would be audio and video recorded and transcribed. The transcriptions came from Zoom transcribe, hand-written notes and the researcher transcribing from video and audio. The researcher employed a qualitative model for data collection and data analysis. After constant comparison and contrast, as well as simultaneous analysis, three emerging themes were identified and the theory was generated.

\subsection{Results}

This study utilized a mixed method to examine students' IC level at the University of Montana, whether there is any statistically significant difference in IC level between students with study abroad (SA) experience and those without SA experience, as well as how students value study abroad programs and intercultural communication. Based on the data from the survey, the descriptive and inferential statistics of the research results are presented first, then followed by the themes and theory generated from the interview data.

The demographic information showed the average age of participants was 24.27 ( $\mathrm{SD}=8.55$, minimum age $=17$, maximum age $=67)$. Among 385 participants, there were 76 freshmen $(19.7 \%), 76$ sophomores $(19.7 \%), 80$ juniors (20.8\%), and 153 seniors (39.7\%). Thirty-five participants have SA experience compared to 350 without SA experience. There were 307 participants with the experience of travelling abroad, opposite to 78 without travelling abroad experience. A majority of participants in this study were seniors, accounting for 40 percent. Most participants identified themselves as Caucasian American/White (320), followed by multiple ethnicities (32), Hispanic/Latino (14), Native American (9), Asian/Pacific Islander (8), and African American/Black (2).

As shown in Table 3, the results of descriptive statistics indicated that the overall students' IC level $(\mathrm{N}=385$, Median = 73) was high. IC of students with SA experience $(\mathrm{N}=35$, Median $=77)$ was higher than that of students without SA experience $(\mathrm{N}=350$, Median $=73)$. 
Table 3. Medians for All Students' IC, IC of Students with and without SA experience

\begin{tabular}{lllll}
\hline & $\begin{array}{l}\text { Total } \\
\text { IC }\end{array}$ & $\begin{array}{c}\text { IC with SA } \\
\text { experience }\end{array}$ & $\begin{array}{l}\text { IC without } \\
\text { experience }\end{array}$ & SA \\
\hline Median & 73 & 77 & 73 & \\
$\mathrm{~N}$ & 385 & 35 & 350 & \\
\hline
\end{tabular}

There were 373 out of 385 participants responded to the last question "What level of intercultural competence do you think you are at $(1=$ low, $2=$ medium, and $3=$ high $)$ ?" in the survey. Only one $(0.3 \%)$ participant self-evaluated himself or herself as low level, 148 participants evaluated themselves as medium (39.7\%) level, and $224(60.1 \%)$ evaluated as high level. It is obvious that more than 60 percent of students think they have high level of IC and almost 40 percent students think their IC level belong to medium.

In order to explore whether there is any statistically significant difference in IC between students with SA experience and those without SA experience, the Mann-Whitney U test was conducted. Table 4 represented the results of the Mann-Whitney U test. There was statistically significant difference in IC level between students with SA experience $($ Median $=77, \mathrm{n}=35$ ) and those without SA experience (Median $=73, \mathrm{n}=350), \mathrm{U}=3922.00, \mathrm{Z}=-3.51, \mathrm{p}<.01$. This meant that students with SA experience did perform differently on the IC in comparison with students without SA experience. The magnitude of the differences was very small, because the value of effect size $r=.07$, according to Cohen's (1988) "criteria of .1 = small effect, . 3 = medium effect, and $.5=$ large effect" (as cited in Pallant, 2016, p. 233). This suggested that SA experience did result in statistically significant difference in IC in this study, but the magnitude of the differences was small.

Table 4. Results of Mann-Whitney U test and Median for IC with and without SA experience

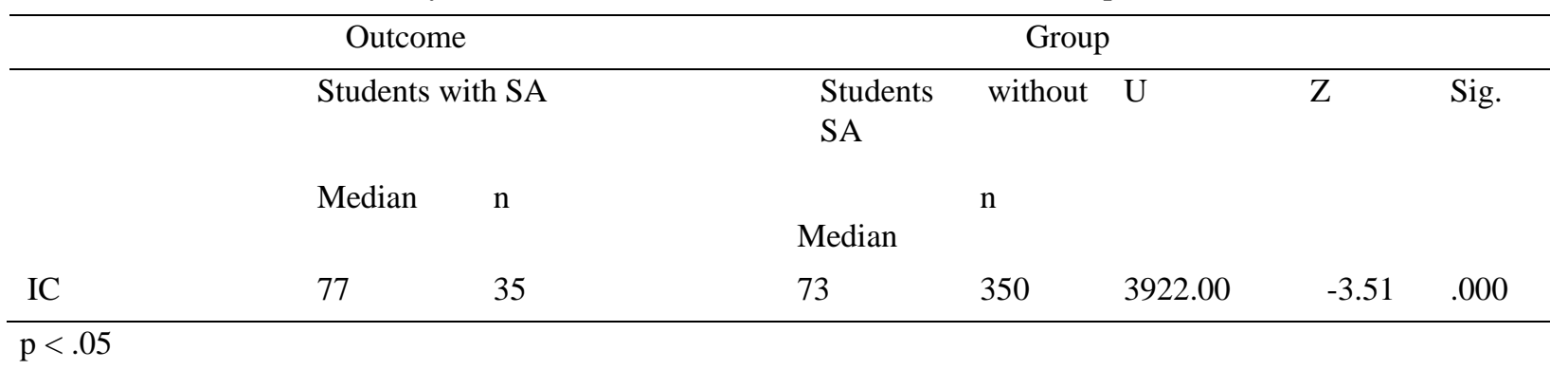

Applying Strauss and Corbin's (1998) procedures for data analysis, during the initial coding stage, open coding was utilized to reduce the clustering of categories; in the intermediate stage, axial coding was used to frequently evaluate the data in order to discern possible interpretive categories; during the final stage, selective coding was employed to develop detailed categories and established a core selection and integrated them into categories, and thus the theory was generated to explain the detailed process of the phenomenon. Consequently, three themes emerged and the theory generated after three stages of data coding. Three themes include: (a) Student with and without study abroad (SA) experience all value study abroad program highly; (b) Study abroad program and traveling broaden students' vision and increase their intercultural experience; (c) Intercultural competence is so important for students' personal, academic and professional development. The emerging theory is: The study abroad program has exerted positive influence on students' IC. The findings from interviews were congruent with, and further supplement, the results from the survey.

\subsection{Discussion}

The above findings are discussed in this section to address two research questions and one central question of this study:

(1) What is the IC level of overall college students at a flagship university in the northwest, United States? What are the IC levels of students who participated in study abroad program and those who didn't participate respectively?

(2) Is there any statistically significant difference in intercultural competence between students with SA experience and those without SA experience?

(3) How do college students at a flagship university in the northwest, United States, value study abroad program and intercultural communication?

\subsubsection{IC Level of College Students}

The findings from quantitative and qualitative data indicated the IC level of overall students at a flagship university in the northwest, United States is relatively high, which is consistent with students' self-evaluation of themselves. To put it another way, students' IC level is satisfactory. The first possible reason for it is most participants were seniors. The 
longer they stay in college, the more knowledge they accumulate about globalization and internationalization, and the more opportunity they have to access cultural differences and IC communication. For another, students hold positive attitudes towards cross-cultural communication. The findings of this study demonstrated that students have realized the importance of cross-cultural interaction, and voluntarily get access to global events and international activities, in order to improve their IC, especially, those participants with SA experience act on the intercultural events more actively. All participants in the interviews held that it is vital to show openness, tolerance and respect when communicating with people from different cultural backgrounds, which has been emphasized by Deardorff (2006), "the attitudes of openness, respect (valuing all cultures), and curiosity and discovery (tolerating ambiguity) are viewed as fundamental to intercultural competence" (p. 255).

The quantitative data indicated that all participants surpassed the three stages of ethnocentrism and stepped into the adaptation stage of ethnorelativism. The qualitative data demonstrated that eight participants fall onto the acceptance stage or adaptation stage. For example, one interviewee with SA experience, called Mary (all names in this study are pseudonyms, in order to maintain the confidentiality of participants), answered the question "what have you obtained from SA experience?" by pointing out the benefits of SA brought her, such as, improvement of language skills, general personal growth, and being more confident, empathetic, decisive and independent in personal, academic and professional life, etc.. Another interviewee was named Lily. Although she had no SA experience, she responded to the question "What do you think would be beneficial to students who want to study abroad?" in a very positive way --"Study abroad is awesome because you're fully immersing yourself, ... there are a lot of benefits of studying abroad, ...you have gained a sense of empathy and understanding that are impossible to get unless you're immersed in the culture".

When asked "how do you feel when you communicate with other people from a different culture?" Lily without SA experience answered that she valued it, respected it and opened her heart and mind to it. She stressed the importance of intercultural communication by saying "I can learn and that hopefully the individual who I'm interacting with can learn, too, and you can just break down the stereotypes in the stigmas that are around each culture..." All participants responded to the question "to what extent do you value across cultural interaction?" in a similar way, that is, they claimed they value intercultural communication or interaction highly. For instance, Mike without SA experience said "I would say it's very high on the scale of value." Susan with SA experience stated "in my own sense of it a high extent..." These examples demonstrated that participants with and without SA experience all have a high intercultural awareness. They value SA experience a lot and believe intercultural communication is super important in today's globalized world.

\subsubsection{IC Level Difference Between Students with and Without SA Experience}

Quantitative finding indicated the IC level of students with SA experience is higher than those without SA experience. This result justified the description of Bennett's model of intercultural sensitivity, “... as one's experience of cultural difference becomes more complex and sophisticated, one's potential competence in intercultural relations increases" (Hammer et al, 2003, p. 423). Qualitative data in this study further supported and confirmed the quantitative results. Participants with SA experience showed more interest in intercultural events and projects, and participated more actively in intercultural activities than those without SA experience. For instance, Susan with SA experience responded to the question "in what ways have you integrated multi-cultural issues as part of your student life?" by saying "I've enjoyed throughout these four years here in the university going to talks and conversations and presentations of visiting scholars, you know, I've gone to a lot of events through Mansfield Center when they bring in..." Mary with SA experience was very active to accumulate intercultural experiences. She volunteered to teach English as a second language at the Lifelong Learning Center and started a Japanese English Conversation Club. She integrated multi-cultural issues in her personal, academic and professional life thoroughly. Oppositely, those without SA experience showed less interest in multi-cultural issues and global activities. Take Mike as an example. He liked to turn to social media for learning about international events, by saying "in my personal life I look at international news to try to follow what's going on with different cultures and trying to see like who's getting along well and who's in conflict, and stuff..." without taking any concrete actions to join in the global events or activities.

With regards to differences in IC level, quantitative results revealed there was statistically significant difference between students who participated in SA program and those who didn't participate. This result is similar to Rust et al's (2013) findings. They found statistically significant increase in the Intercultural Development Inventory (IDI) scores after the study abroad experience, and intercultural coursework combined with study abroad experience had a positive impact on IC development. This result is also consistent with Pedersen's (2010) research. He compared scores of students' IDI and discovered that there was a statistically significance difference in the scores between students who participated in activities for developing IC and those who didn't participate and stayed at home. The result of this study also supports Anderson and Lawton's (2011) finding. They used the Global Perspective Inventory (GPI) and the Intercultural Development Inventory (IDI) to investigate students' intercultural development between students with SA 
experience and those on campus, and revealed that students in a SA program had gained much more in intercultural development than those who were on campus.

\subsubsection{Students' Attitudes and Ideas About SA Program and IC Communication}

Given the fact that the flagship university in the northwest, United States is less diverse than universities in other parts of the United States, students in this study were looking for ways to become more familiar with those from other countries and their cultures. Students held a positive attitude towards SA program and intercultural communication. They valued SA program highly. They believed that SA program and traveling had broadened their vision and increase their intercultural experience. For instance, in responding to the question "What have you obtained from the SA experience?" Susan with SA experience answered,

I definitely have a lot more relationships... Also it definitely gave me a more globalized sense of the world, like when I think of problems, I definitely have started to think of them on a more global scale, and look at examples from every other country in the world to see how they have addressed issues that may be just starting to develop here, or how issues developed in other countries, and how that could have been avoided. We can learn so much from one another.

They emphasized that intercultural communication is so important for their personal, academic and professional development and the SA program has exerted positive influence on their IC. Take Lily as an example. She claimed that via intercultural communication, she learned how to be "empathetic, compassionate and respectful even when I'm not respected..." Erica expressed similar idea and she added that "I'm more adventurous. I'm more open, taking risks. I am more interested in other cultures... I'm more flexible, less rigid..." These results are consistent with findings of other studies, such as Maharaja (2009) employed a quantitative research method in his doctoral dissertation and found that the SA experience had a positive influence on students' IC and personal development.

To summarize, findings from interviews were congruent with the results from the survey, as well as students' self-evaluation. Data from survey indicated the IC level of overall students are high, falling into Bennett's DMIS adaptation stage. The IC level of students with SA experience is significantly different from that of students without SA experience. Most students think their IC levels are high. Data from interviews showed students' awareness of IC is high. Compared to Bennett's DMIS continuum, they have stepped from ethnocentrism into ethnorelativism: the acceptance stage or/and adaptation stage. They hold very positive attitudes towards SA programs and intercultural communication. They value SA programs highly. They, no matter whether participated in SA programs, all think SA experience is very valuable and beneficial to their personal, academic and professional development.

\subsection{Limitations}

The sample only consisted of 35 students who participated in SA programs and 350 students who did not participate. The proportion of these two groups of students is unbalanced. A small sample size of students with SA experience does not represent all characteristics of the whole population. The future study needs to recruit a large sample in order to generalize the research results to the population. This study only explored the IC level and the difference in IC between students with SA experience and those without SA experience. Whether other factors, such as students' GPA, curricula areas, gender, ethnicity or race, family background, as well as social status, have an impact on IC and IC development, need to be explored in future studies. Finally, a longitudinal study on the link and relationship between SA experience and IC development will provide an insight on how students internalized their intercultural learning before, during and after SA programs. These limitations may be regarded as recommendations for future studies on SA and IC.

\subsection{Implications and Recommendations}

Although participating in study abroad is one way to strengthen or enhance students' IC, not all students catch the opportunity to study abroad. Pongitory (2020) pointed out "researchers reported less than 20 percent of college students engage in this opportunity" (p. 21). There are many factors that prevent students from participating in study abroad programs. These factors include "cost, distance, family obligations, job restrictions, financial limitations and time restraints" (Wickline et al., 2020, p. 132). Kurt et al. (2013) stated there are two main obstacles for participating in SA programs and they are timing and program duration. Therefore, leaders in institutions of higher education need to create more opportunities and encourage students to participate in SA programs. Various SA options may be offered to students with different needs, such as full-semester programs, short-term programs or partial semester programs, and global internship programs (Stebleton et al., 2013). Wickline et al. (2020) suggested for students who still "are unable to, unwilling to, or disinterested in study abroad, campuses need to get creative at home" (p. 132), if SA programs of different lengths cannot cater to all students.

Some research demonstrated there are positive relationship between career development and study abroad (Hubbard \& Rexeisen, 2020). Hubbard and Rexeisen (2020) stressed "the growing body of evidence (Carlson, 2017; DesJardins et 
al., 1999; Dwyer 2004; Rexeisen et al., 2005) [indicates] that study abroad provides a positive return for institutions of higher education" (p. 17). Therefore, leaders in institutions of higher education need to do everything to maximize the potential benefits that SA programs have brought, increase more investment in SA programs, as well as devote more energy, time and resources to help prepare students for their future employment. (Hubbard \& Rexeisen, 2020)

\section{Conclusion}

The main purpose of this study was to explore what college students' IC level was, whether there was statistically significant difference in IC between students with SA experience and those without SA experience, as well as how students value SA program and intercultural communication. The findings revealed that the participants' IC level was medium high. Students with SA experience did perform differently compared to students without SA experience, with respect to IC level. Their IC level was higher on average. Study abroad programs influence students' IC in a positive way. Intercultural competence plays a vital role in students' personal, academic and professional development. This study supports and supplements more evidence that SA programs have positive impacts on IC.

The fact that the overall IC level of college students at a flagship university in the northwest, United States was high is satisfying, but the number of students who participate in study abroad programs is quite small. It is imperative for leaders, faculty and staff to encourage students to participate in SA programs, in order to improve their knowledge, skills and IC. Schools need to offer more financial support, academic guidance and spiritual encouragement for students who are interested in the SA program, because going abroad to study brings a lot of benefits. Except SA programs, taking some international courses or disciplines that are closely related to IC and cultures is also an effective strategy. Finally, making friends and communicating with people coming from different cultural backgrounds is a good way to improve their IC level as well.

\section{References}

Anderson, P. H., \& Lawton, L. (2011). Intercultural development: Study abroad vs. On-campus study. Frontiers: The Interdisciplinary Journal of Study Abroad, 21, 86-108.

Anderson, P. H., \& Lawton, L. (2015). Student motivation to study abroad and their intercultural development. Frontiers: The Interdisciplinary Journal of Study Abroad, 38-52.

https://ir.stthomas.edu/cgi/viewcontent.cgi?article=1022\&context=ocbmgmtpub

Anderson, P. H., Lawton L., Rexeisen, R. J., \& Hubbard A. C. (2005). Short-term study abroad and intercultural sensitivity: A pilot study. International Journal of Intercultural Relations, 30(4), 457-469. https://www.sciencedirect.com/science/article/pii/S0147176705001641

Bennett, M. J. (2004). Becoming Interculturally Competent. In Wurzel, J. (Ed). Toward multiculturalism: A reader in multicultural education (2nd ed., pp. 62-77). Newton, MA: Intercultural Resource Corporation.

Braskamp, L. A., Braskamp, D. C., \& Merrill, K. (2009). Assessing progress in global learning and development of students with education abroad experiences. The Interdisciplinary Journal of Study Abroad, 18, 101-118. https://files.eric.ed.gov/fulltext/EJ883693.pdf

Deardorff, D. K. (2006). Identification and assessment of intercultural competence as a student outcome of internationalization. Journal of Studies in International Education, 10(3), 241-266. https://journals.sagepub.com/doi/abs/10.1177/1028315306287002

Deardorff, D. K. (2009). The SAGE handbook of intercultural competence. Thousand Oaks, CA: Sage.

Fantini, A. (2009). Assessing intercultural competence: Issues and Tools. In D. K. Deardorff (Ed.), The SAGE handbook of intercultural competence (pp. 456-476), Thousand Oaks, CA: Sage.

Hammer, M. R., Bennett, M. J., \& Wiseman, R. (2003). Measuring intercultural sensitivity: The intercultural development inventory. International Journal of Intercultural Relations, 27, 421-443.

Heinzmann, S., Kunzle, R., Schallhart, N., \& Muller, M. (2015). The effect of study abroad on intercultural competence: Results from a longitudinal quasi-experimental study. Frontiers: The Interdisciplinary Journal of Study Abroad, 26, 187-208. https://doi.org/10.1080/01434632.2015.1073737

Hubbard, A., \& Rexeisen, R. J. (2020). Investing in study abroad and cultural engagement: A win-win for career development. Frontiers: The Interdisciplinary Journal of Study Abroad, 32(3), 3-21.

King, P.M., Perez, R. J \& Shim, W (2013). How College Students Experience Intercultural Learning: Key Features and Approaches. Journal of Diversity in Higher Education, 6(2), 69-83.

Kurt, M. R., Olitsky, N. H., \& Geis, P. (2013). Assessing global awareness over short-term study abroad sequence: a factor analysis. Frontiers: The Interdisciplinary Journal of Study Abroad, 23, 22-41. 
Lustig, M. W., \& Koester, J. (2013, 7th ed). Intercultural Competence: Interpersonal Communication Across Cultures. New York: Pearson

Maharaja, G. (2009). An "Island" Study Abroad Program and its Impact on the Intercultural Sensitivity and Cross-Cultural Adaptability of its Participants: Perspectives from a Research-Intensive University. Doctoral degree dissertation, Duquesne University 3365462

Maharaja, G. (2018). The Impact of Study Abroad on College Students' Intercultural Competence and Personal Development. International Research and Review, 7(2), 18-41. https://files.eric.ed.gov/fulltext/EJ1188735.pdf

Mapp, S. C. (2012). Effect of short-term study abroad programs on students' cultural adaptability. Journal of Social Work Education, 48(4), 727-737.

Marx, H., \& Moss, D. M. (2011). Please mind the culture gap: Intercultural development during a teacher education study abroad program. Journal of teacher education, 62(1), 35-47.

Mirzaei, A., \& Forouzandeh, F. (2013). Relationship between intercultural communicative competence and L2-learning motivation of Iranian EFL learners. Journal of Intercultural Communication Research, 42(3), 300-318.

Olson, J. E., \& Lalley, K. (2012). Evaluating a short-term, first-year study abroad program for business and engineering undergraduates: understanding the student learning experience. Journal of Education for Business, 87(6), 325-332.

Pallant, J. (2016). SPSS Survival Manual (6 $6^{\text {th }}$ ed). Allen \& Unwin.

Pedersen, P. (2010). Assessing intercultural effectiveness outcomes in a year-long study abroad program. International Journal if Intercultural Relations, 34, 70-80.

Petrie-Wyman, J. L., Murrell, A., \& Schultz, B. (2020). Recognizing the impact of study abroad on women business students: Results from a mixed methods Global Competency Survey. Frontiers: The Interdisciplinary Journal of Study Abroad, 32(3), 22-50.

Pongitory, A. A. (2020). Experiential learning during study abroad sojourns: Catalyst for global competence development (Publication No. 28150678) [Doctoral dissertation, Saint Joseph's University]. ProQuest Dissertations and Theses Global.

Rust, K. G., Forster, B., Niziolek, A., \& Morris, C. M. (2013). Study abroad and intercultural coursework: Their effects on change in intercultural competence. International Research and Review, 3(1), 3-13. https://eric.ed.gov/?id=EJ1149919

Sakurauchi, Y. H. (2014). Teaching and Learning for Intercultural Sensitivity: A Cross-Cultural Examination of American Domestic Students and Japanese Exchange Students. (Publication No. 3615841) [Doctoral dissertation, Portland State University]. ProQuest Dissertations and Theses Global. (Doctoral dissertation).

Saricoban, A., \& Oz, H. (2014). Research into pre-service English teachers' intercultural communicative competence (ICC) in Turkish context. The Anthropologist, 18(2), 523-531.

Stebleton, M. J., Soria, K. M., \& Cherney, B. (2013). The high impact of education abroad: College students' engagement in international experiences and the development of intercultural competencies. Frontiers: The $\begin{array}{llllll}\text { Interdisciplinary } \quad \text { Journal } & \text { Abroad, } & \text { 22(1), } & \text { 1-24. }\end{array}$ https://conservancy.umn.edu/bitstream/handle/11299/150028/1/Stebleton-Soria-Cherney-FRONTIERS\%202012-1 3.pdf

Stemler, S. E., Imada, T., \& Sorkin, C. (2014). Development and validation of the Wesleyan Intercultural Competence Scale (WICS): A tool for measuring the impact of study abroad experiences. Frontiers: The Interdisciplinary Journal of Study Abroad, 24, 25-47. https://files.eric.ed.gov/fulltext/EJ1062089.pdf

Strange, H., \& Gibson, H. J. (2017). An investigation of experiential and transformative learning in study abroad programs. Frontiers: The Interdisciplinary Journal of Study Abroad, 29(1), 85-100.

Strauss, A., \& Corbin, J. (1998). Basics of qualitative research: Techniques and procedures for developing grounded theory (2nd ed.). Thousand Oaks, CA: Sage.

Tarchi, C., Surian, A., \& Daiute, C. (2019). Assessing study abroad students' intercultural sensitivity with narratives. European Journal of Psychology of Education, 34(4), 873-894.

Weaver, G. R. (1998). Contrasting and comparing cultures. In G. R. Weaver (Ed.), Culture communication and conflict (pp. 72-77). Needham Heights, MA: Simon and Schuster

Wickline, V. B. G., Shea, A. M., Young, C. D., \& Wiese, D. (2020). Increasing intercultural competence in undergraduate education: Study abroad is a viable way, but not the only way. Frontiers: The Interdisciplinary 
Journal of Study Abroad, 32(3), 126-155.

Williams, T. R. (2005). Exploring the impact of study abroad on students' intercultural communication skills: adaptability and sensitivity. Journal of Studies in International Education, 9(4), 356-371. https://doi.org/10.1177/1028315305277681

\section{Copyrights}

Copyright for this article is retained by the author(s), with first publication rights granted to the journal.

This is an open-access article distributed under the terms and conditions of the Creative Commons Attribution license which permits unrestricted use, distribution, and reproduction in any medium, provided the original work is properly cited. 